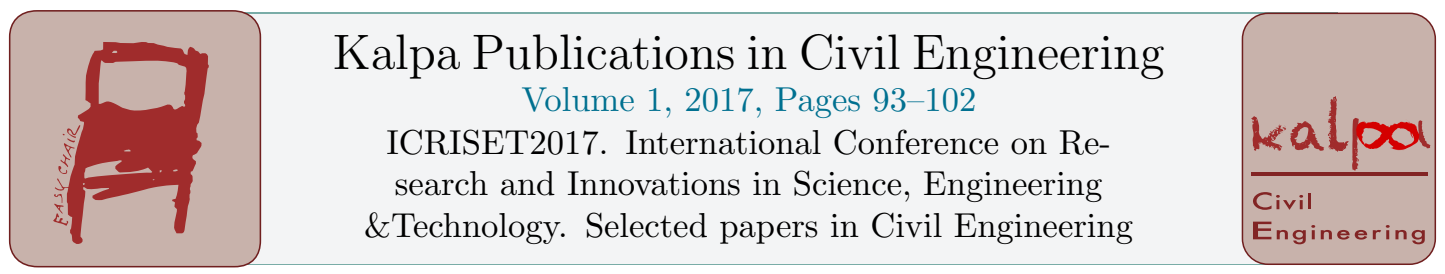

\title{
Performance Based Assessment of Seismic Response Factor for SMRF Staging Elevated Water Tank
}

\author{
Kashyap N. Patel ${ }^{1}$ and Jignesh A. Amin ${ }^{2}$ \\ ${ }^{1}$ P.G. Student, Department of Civil Engineering, \\ Sardar Vallabhbhai Patel Institute of Technology, \\ Vasad-388306 \\ Gujarat, India. \\ Email: kashyapsvit.011@gmail.com \\ ${ }^{2}$ Professor, Department of Civil Engineering, \\ Sardar Vallabhbhai Patel Institute of Technology, \\ Vasad-388306 \\ Gujarat, India. \\ Email:jigneshamin.civil@svitvasad.ac.in
}

\begin{abstract}
RC staging water tanks are essential facilities that are expected to remain operational even after sever earthquakes. The seismic design codes/standards of most countries incorporate the nonlinear response of a structure through a 'seismic response factor' (R). This factor permits a designer to use a linear elastic force based design while accounting for nonlinear behavior and deformation limits. In this paper orderly approach is deputed to determine the seismic response factor of elevated water tank having different soil flexibility. For nonlinear static pushover analysis finite element method is used. The capacity curve of each model is generated and the ' $R$ ' factors are obtained such wise. The impact of soil flexibility on seismic response factor of RC framing tank is evaluated. ' $R$ ' factors are determined for existing tanks at two performance level.
\end{abstract}




\section{Introduction}

The liquid containing RC storage tanks are significant structure in water distribution. Tanks should remain functional even after major earthquakes. Current FBD method is used by earthquake resistant design codes permits the earthquake design of structures to be based on static or dynamic analysis of elastic models of the structure using elastic design spectra. The codes expect that structures will undergo inelastic deformations only in major earthquake incident; therefore, such inelastic nature is usually consolidated into the design by dividing the elastic spectra by a response modification factor which decreases the spectrum from its original elastic demand level to a design level. The two major factors determining seismic response factors are the structural ductility and over-strength capacity. For tank resting on flexible foundation the elastic period and increases damping of the soil-structure elastic system, the structural ductility could also be influence by frequency-dependent foundation-soil compliances. For inelastic structure resting on flexible soil, the inelastic spectra ordinates are greater than for elastic systems when presented in terms of flexible soil structure's period. This indicates that the ' $R$ ' factors, which are presently not influenced by the soil flexibility effect, could be exchanged. The value of response modification factor of SMRF staging water tank are given in IS 1893 (Part-II) 2002, which is arrived at empirically based on engineering judgment. The values of response reduction factor of elevated water tank adopted by difference codes/standards are summaries in TABLE 1. Present research does not show any detailed groundwork on which a value of 2.5 is fixed for RC elevated water tanks in the Indian standard IS:1893

Mondal et al. [1] estimated the real values of response reduction factor for actual RC moment frame structure designed and detailed using the Indian codes for earthquake and RC designs and for ductile detailing. Author concluded that codes recommend higher than real value of ' $R$ ' for $\mathrm{RC}$ frame that is not acceptable. Amin and Tamboli [2] evaluated the ' $\mathrm{R}$ ' factor of $\mathrm{RC}$ frame strengthen using the different types of bracing system. Author concluded that ' $R$ ' factor is considerably affected by the type and arrangement of bracing system. Masoudi et al. [3] discusses the seismic behavior and failure mechanism of RC frame and shaft supported tanks. The impacts of sever earthquakes, Tank full and empty conditions and the $\mathrm{P}-\Delta$ effects on the seismic behaviour of RC tanks have been observed by performing linear and nonlinear response history analysis. Livaoglu and Dogangun [4] investigated the effects of soil structure interaction on the sloshing response of elevated water tank for two different supporting system and six different soil profile including both embedded and surface foundation cases. Author concluded that the soil structure interaction and the supporting systems structural property affect the sloshing response of fluid within the container. Ghateh et al. [5] presented a methodical approach to determine the response modification factors for total 48 types of elevated tank of different capacity and RC frame dimensions commonly used in industry. They have suggested not to use the same response reduction factor for different sort of tanks and also concluded that the variation in staging height and tank capacity can significantly affect the $\mathrm{R}$ factor. Dutta et al. [6] had studied the effect of soil flexibility on two significant dynamic characteristics of RC frame staging tanks with a few optional configurations. Analysis without considering soil flexibility may lead to lower or higher estimation of seismic base shear of RC frame staging tanks with any optional staging patterns considering fluid-structure interaction. Amin et al. [7] made efforts for component-wise computation of response reduction factor for elevated water tank having equal staging height but different capacities. They have concluded that the value of response reduction factor for RC staging tank is significantly influenced by time period, capacity of tank, seismic zone.

One constant R-value for elevated water tank cannot reflect the expected inelastic behavior of elevated water tanks supported on various types of soil. It is essential to consider the effect of soil flexibility to avoid erroneous and underestimated or overestimated response quantity. The 
aim of the present study is to determine the seismic response factors for existing realistic RC framed staging elevated water tank, considering the effects of soil- flexibility and comparing these values with the value suggested in the seismic design code.

TABLE I. VALUES OF 'R' FROM DIFFERENT CODE

\begin{tabular}{ll}
\hline \multicolumn{1}{c}{ Codes } & \multicolumn{1}{c}{ R value } \\
\hline IBC 2000 / FEMA 368 & 1.5 to 3.0 \\
\hline AWWA D110 & 2 to 2.75 \\
\hline ACI 350.3 & 2.0 to 4.75 \\
\hline RCC frame support IS:1893 - 2002 (Part - 2) SMRF & 2.5 \\
\hline RCC frame support IS:1893 - 2014 (Part - 2) SMRF & 4 \\
\hline
\end{tabular}

\section{Component of ' $\mathrm{R}$ ' Factor}

Generally, the response reduction factor is defined as a component of various parameters such as strength, ductility and redundancy of the structural system.

\subsection{Strength Factor $\left(\mathrm{R}_{\mathrm{s}}\right)$ :}

$$
R=R_{S} \times R_{\mu} \times R_{R}
$$

Strength factor (Rs) accounts for the yielding of a structure at load higher than the design load due to various partial safety factors, strain hardening, oversized members, confinement of concrete. Non-structural elements also contribute to the over strength. The over strength factor generally vary with seismic zones, height of structure and design gravity loads/capacity of water tank. The strength factor $\left(R_{S}\right)$ is ratio of maximum base shear $(\mathrm{Vu})$ to the design base shear $(\mathrm{Vd})$.

\subsection{Ductility Factor $\left(\mathrm{R}_{\mu}\right)$ :}

The seismic response parameters of displacement capacity, ductility and ductility ratio are closely inter-related. Displacement ductility ratio is generally defined as the ratio of maximum displacement to the displacement at yield.

Miranda and Bertero (1994) summarized and reworked the $R_{\mu}-\mu-T$ relationships developed by a number of researchers including Newmark and Hall (1982), Riddell and Newmark(1979), and Krawinkler and Nassar (1992), in addition to developing general $R_{\mu}-\mu$-T equations for soft, alluvium and rock soil sites. The Miranda and Bertero equations for ductility factor shown below was developed using 124 ground motions recorded on different soil conditions, and assumed 5\% of critical damping.

$$
R_{\mu}=\frac{\mu-1}{\Phi}+1
$$

Where,

Rock sites: $\Phi=1+\frac{1}{10 T-\mu T}-\frac{1}{2 T} e^{-1.5(\ln (T)-0.6)^{2}}$

Alluvium sites: $\Phi=1+\frac{1}{12 T-\mu T}-\frac{2}{5 T} e^{-2(\ln (T)-0.2)^{2}}$

Soft soil sites: $\Phi=1+\frac{T_{g}}{3 T}-\frac{3 T_{g}}{4 T} e^{-3\left(\ln \left(T / T_{g}\right)-0.25\right)^{2}}$ 
Where, $\mathrm{Tg}$ is the predominant time period of the ground motion.

\subsection{Redundancy Factor $\left(\mathrm{R}_{\mu}\right)$ :}

It mainly relies on the vertical seismic framing numbers. Yielding at one location in the structure does not indicate yielding of the whole structure. Hence, the load distribution, due to redundancy of the structure, provides additional safety margin. RC structural systems with lateral load resisting frames are normally considered as redundant structure, as each of the seismic frames is designed to transfer the seismic forces to the soil. Following the conservative assumption, $R_{R}=1.0$ is used in this study.

\section{Structural Performance Limit}

The terminology of the seismic ' $R$ ' factor is unified to the selected performance limit state of the system. The Indian codes do not justify the limit state corresponding to which values of response reduction factor are suggested in this code. In this study, two performance limits are taken to determine response reduction factor for the considered water tank. The performance Limit 1 or PL1 based on the Life Safety limit state of RC frame member defined in FEMA-356. This limit state is termed at the member level (in terms of the permissible plastic hinge rotation at member ends). The Performance Limit 2 or PL2 is defined as the point corresponding to the maximum base shear on the force-displacement relationship curve of structures. This limit state is defined at the structural level (in terms of the ultimate capacity of the structural system). TABLE II shows the 'local' deformation limits provided in FEMA-356 of beam elements in terms of plastic hinge rotations for RC moment resisting frame. TABLE III shows similar confined values for different performance levels of column rotation. These specific values are for flexural failures of a member. Therefore, to use these confined values, one should ensure that the collapse of an element is governed by flexural demands, and shear failure, for example, Collapse does not occurred before these limits are reached.

TABLE II. PLASTIC ROTATION LIMIT FOR RC BEAM, AS PER FEMA 356

\begin{tabular}{|c|c|c|c|c|c|}
\hline \multirow{2}{*}{$\frac{p-p^{\prime}}{p_{b a l}}$} & \multirow{2}{*}{$\begin{array}{l}\text { Trans } \\
\text { Reinf }\end{array}$} & \multirow{2}{*}{$\frac{v}{b_{w} d \sqrt{f_{c}}}$} & \multicolumn{3}{|c|}{ Acceptance criteria } \\
\hline & & & $\mathrm{IO}$ & LS & $\mathrm{CP}$ \\
\hline$\leq 0.0$ & $\mathrm{C}$ & $\leq 3$ & 0.010 & 0.02 & 0.025 \\
\hline$\leq 0.0$ & $\mathrm{C}$ & $\leq 6$ & 0.005 & 0.01 & 0.02 \\
\hline
\end{tabular}

TABLE III. PLASTIC ROTATION LIMIT FOR RC COLUMN, AS PER FEMA 356

\begin{tabular}{|c|c|c|c|c|c|}
\hline \multirow{2}{*}{$\frac{p-p^{\prime}}{p_{b a l}}$} & \multirow{2}{*}{$\begin{array}{l}\text { Trans } \\
\text { Reinf } \\
\end{array}$} & \multirow{2}{*}{$\frac{v}{b_{w} d \sqrt{f_{c}}}$} & \multicolumn{3}{|c|}{ Acceptance criteria } \\
\hline & & & $\mathrm{IO}$ & $\mathrm{LS}$ & $\mathrm{CP}$ \\
\hline$\leq 0.1$ & $\mathrm{C}$ & $\leq 3$ & 0.005 & 0.015 & 0.020 \\
\hline$\leq 0.1$ & $\mathrm{C}$ & $\geq 6$ & 0.005 & 0.012 & 0.016 \\
\hline$\geq 0.4$ & $\mathrm{C}$ & $\leq 3$ & 0.003 & 0.012 & 0.015 \\
\hline$\geq 0.4$ & $\mathrm{C}$ & $\geq 6$ & 0.003 & 0.010 & 0.012 \\
\hline
\end{tabular}




\section{Soil Structure Interaction}

Soil-structure interaction is interdisciplinary field which involves structural and geotechnical engineering. A more logical solution of soil-flexibility problem can be achieved with computational validity and precision by suitable analysis. The behavior of soil can be conveniently simulated using a set of elastic springs. The underneath soil flexibility can be modeled with equivalent translation, rocking and torsional elastic stiffness based on soil properties as using equations given by Whitman and Richart (TABLE IV).

TABLE IV. EQUIVALENT SPRING STIFFNESS FOR RAFT FOOTING

\begin{tabular}{|c|c|c|c|c|}
\hline Mode & Vertical & Horizontal & Rocking & torsion \\
\hline \multirow[t]{2}{*}{ Stiffness } & $4 G R$ & $8 G R$ & $8 G R^{3}$ & $16 G R^{3}$ \\
\hline & $\overline{1-\mu}$ & $\overline{2-\mu}$ & $\overline{3(1-\mu)}$ & $3(1-\mu)$ \\
\hline \multirow[t]{2}{*}{ Mass ratio } & $m(1-\mu)$ & $m(2-\mu)$ & $m I_{x}(2-\mu)$ & $I_{z}$ \\
\hline & $4 \mathrm{p} R^{3}$ & $8 p R^{3}$ & $8 p R^{3}$ & $\overline{\mathrm{p} R^{5}}$ \\
\hline \multicolumn{5}{|c|}{$\mathrm{Ix}, \mathrm{Iz}=$ mass moments of inertia around a horizontal, vertical axis, } \\
\hline \multicolumn{5}{|c|}{ respectively; damping ratio $=\mathrm{C} / \mathrm{Ccr}$ where $\mathrm{Ccr}=2(\mathrm{Km}) 1 / 2$ or } \\
\hline \multicolumn{5}{|c|}{$\mathrm{Ccr}=2(\mathrm{KI}) 1 / 2$ for translational or rotational modes of vibration, } \\
\hline
\end{tabular}

Three different material properties of soil stratum i.e. hard, medium and soft soil conditions were selected in order to study the effect of SSI. The linear elastic material behavior was assumed for soil. The elastic properties and calculated equivalent spring constants of considered soils in different direction are shown in Table TABLE V and TABLE VI respectively.

TABLE IV. ELASTIC PROPERTIES USED FOR SOIL

\begin{tabular}{lccc}
\hline Type of soil & $\begin{array}{l}\text { Shear modulus } \\
\mathrm{G}\left(\mathrm{kN} / \mathrm{m}^{2}\right)\end{array}$ & $\begin{array}{l}\text { Poisson's } \\
\text { ratio } \mu\end{array}$ & $\begin{array}{l}\text { Unit weight of } \\
\text { saturated soil }\left(\mathrm{kN} / \mathrm{m}^{2}\right)\end{array}$ \\
\hline Hard soil & 94175 & 0.5 & 19.4 \\
\hline Medium soil & 54089 & 0.5 & 18.5 \\
\hline Soft soil & 12900 & 0.5 & 13.5 \\
\hline
\end{tabular}

TABLE V. SPRING STIFFNESS CONSIDERED IN WATER TANK

\begin{tabular}{ccc}
\hline Type of soil & $\begin{array}{c}\text { Degrees of } \\
\text { freedom }\end{array}$ & $\begin{array}{c}\text { Spring constant } \\
\left(\mathrm{kN} / \mathrm{m} / \mathrm{m}^{2}\right)\end{array}$ \\
\hline Hard soil & Horizontal & 15852.45 \\
\hline & Vertical & 23778.69 \\
\hline & Rocking & 1613908 \\
\hline Medium soil & Torsion & 1613908 \\
\hline & Horizontal & 9104.78 \\
\hline & Vertical & 13657.18 \\
\hline
\end{tabular}




\begin{tabular}{ccc}
\hline & Rocking & 926941.1 \\
\hline & Torsion & 926941.1 \\
\hline Soft soil & Horizontal & 2171.45 \\
\hline & Vertical & 3257.18 \\
\hline & Rocking & 221071.6 \\
\hline & Torsion & 221071.6 \\
\hline
\end{tabular}

\section{Description and Modeling of Water Tank}

In present study, ' $\mathrm{R}$ ' factor of existing $\mathrm{RC}$ frame staging elevated water tanks having a capacity of $1000 \mathrm{~m}^{3}$ evaluated with and without considering flexibility of soil. The grade of the concrete is M25 and steel reinforced of grade Fe415 is used. The tank is situated at Gandhidham, Gujarat (seismic zone-V). The typical configuration of staging system at the base is shown in fig 1. The brief structural detailing and description of considered elevated water tank is given in TABLE VII

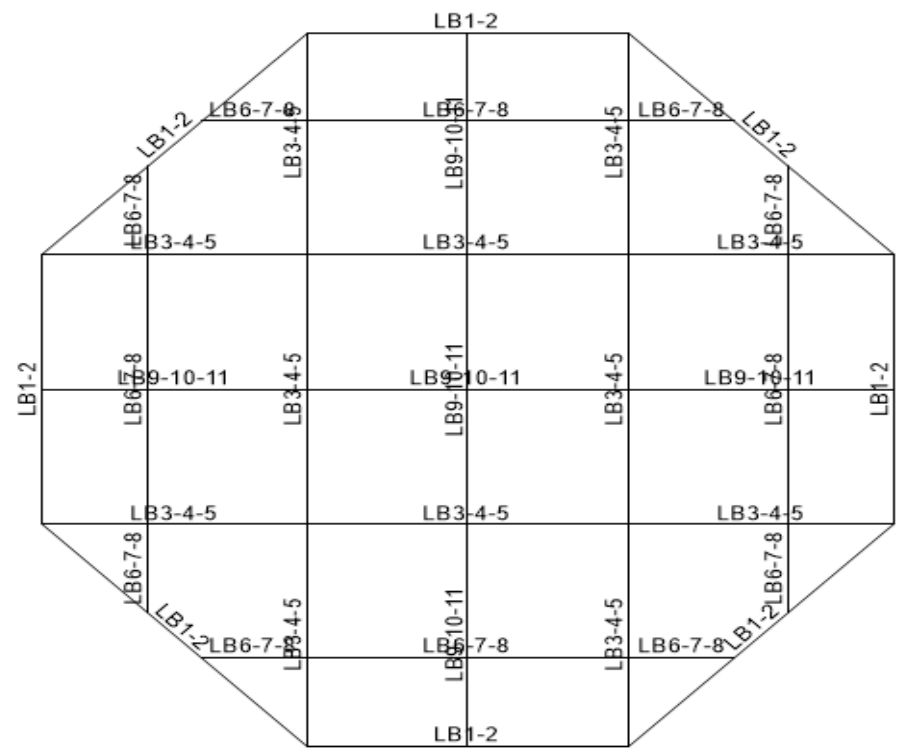

FigureI. PLAN CONFIGURATION AT BASE LEVEL

Table VI. DETAILED DESCRIPTION OF TANK

\begin{tabular}{ll}
\hline \multicolumn{1}{c}{ Capacity } & $1000 \mathrm{~m}^{3}$ \\
\hline Height of staging & $20 \mathrm{~m}$ \\
\hline Seismic Zone & $\mathrm{V}$ \\
\hline Tie Beam Levels & Plinth $+5 \mathrm{~m} \mathrm{c} / \mathrm{c}$ \\
\hline Column Size & 650 \\
\hline Reinforcement in Column & $16-20 \mathrm{~mm}$ \\
\hline Plinth Beam & $400 \times 600$ \\
\hline Tie of Beam & $400 \times 600$ \\
\hline
\end{tabular}




\begin{tabular}{ll}
\hline Bottom Slab Beam & $350 \mathrm{X} 1200$ \\
\hline No. of Column & 12 \\
\hline Length of Column & 5 \\
\hline Reinforcement in Columns & $16-20 \#$ \\
\hline Ground beam 1,2 & $2-16 \#+4-20 \#$ (top)6-16\#(bottom) \\
\hline Ground beam 3,4 & $4-16 \#+4-20 \#$ (top),4-16\#+2-20\#(bottom) \\
\hline Tie beam 1,2 & $4-16 \#+3-20 \#$ (top)4-16\#+2-20\#(bottom) \\
\hline Tie beam 3,4 & $4-16 \#+4-20 \#$ (top),4-16\#+3-20\#(bottom) \\
\hline Lower ring beam B1,B2 & $4-20 \#+6-25 \#$ (top),5-25\#+3-12\#(bottom) \\
\hline Lower ring beam B3,B4,B5 & $4-20 \#+8-25 \#+($ top),10-25\# \\
\hline Lower ring beam B6,B7,B8 & $2-16 \#+6+20 \#+($ top),6-20\# \\
\hline Lower ring beam B9,B10,B11 & $4-16 \#+5-20 \#$ (top),8-20\#(bottom) \\
\hline
\end{tabular}

Sap 2000 V15 software is used to perform nonlinear static pushover analysis of considered tank. The RC beams and columns are modeled as three dimensional frame elements with center line dimension. Different parameters such as weight of staging, weight of container, weight of convective and impulsive masses, C.G of tank are computed as per guidelines given by IITKGSDMA guidelines and then this weights are assigned at the appropriate height of the structure. Fig. 2 shows the modeling of typical tank for the pushover analysis. Walls and domes/slabs are assumed to behave as rigid diaphragms. The diaphragm action of a slab was considering by assigning a rigid link at the floor level of container. Damping ratio of 5 percent is assumed. Flexural $\left(\mathrm{M}_{3}\right)$, axial biaxial moment $\left(\mathrm{P}-\mathrm{M}_{2}-\mathrm{M}_{3}\right)$ plastic hinges are assigned to each ends of the beams and columns respectively, where the resultant moments under gravity and lateral loads are maximum. Shear hinges were assigned at the ends of a beam. In Pushover analysis, first a "gravity push" was applied with full dead load, convective mass, impulsive mass and $25 \%$ of live load. Next a 'lateral push' was applied at the C.G. of the container to obtain the push over curve.

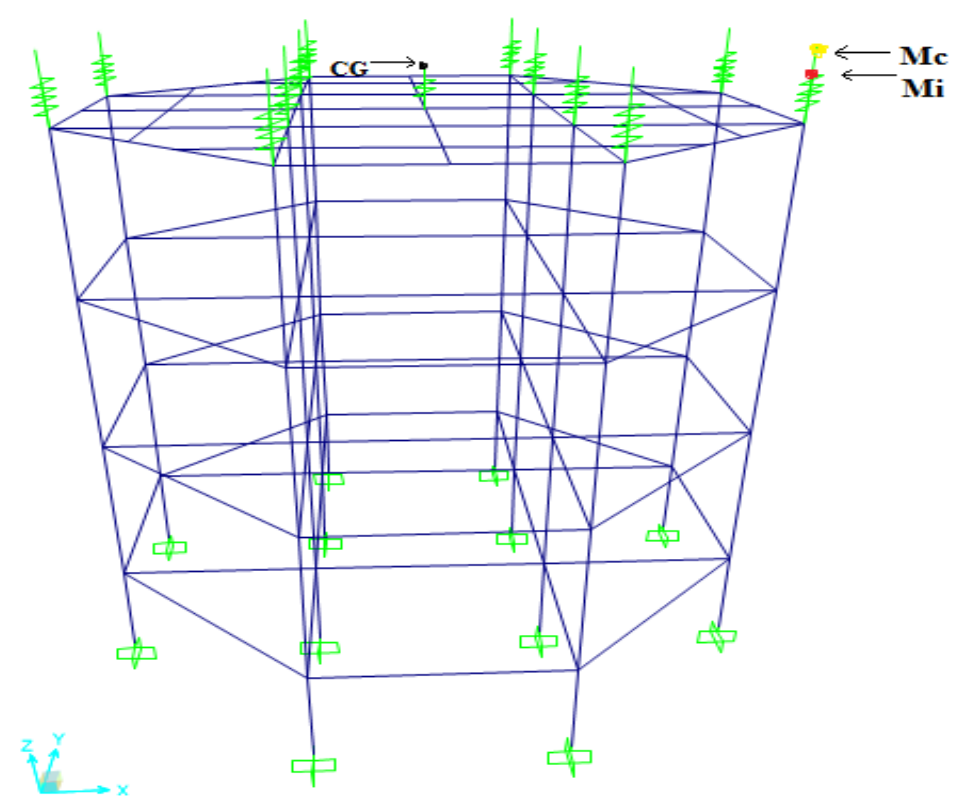

FigureII. MODELING OF WATER TANK FOR PUSHOVER ANALYSIS 


\section{Pushover Curves for RC Staging elevated Water Tank}

From the pushover analysis, the base shear $(V)$ versus roof displacement $\left(\Delta_{\text {roof }}\right)$ curve of the structure, usually called static capacity curve, is determined. In static nonlinear procedure estimation of targeted displacement is required. The target displacement works as an estimate of the maximum displacement of the selected joint of the structure subjected to design earthquake. The node associated with the center of mass at CG of container is often the used as target.

Fig 3, 4, 5 and 6 shows the pushover curves and their bi-linear representations (dotted lines) for considered elevated water tanks supported on different soil conditions. As stated earlier two performance limits PL1 and PL2 are considered in the evaluation of R.

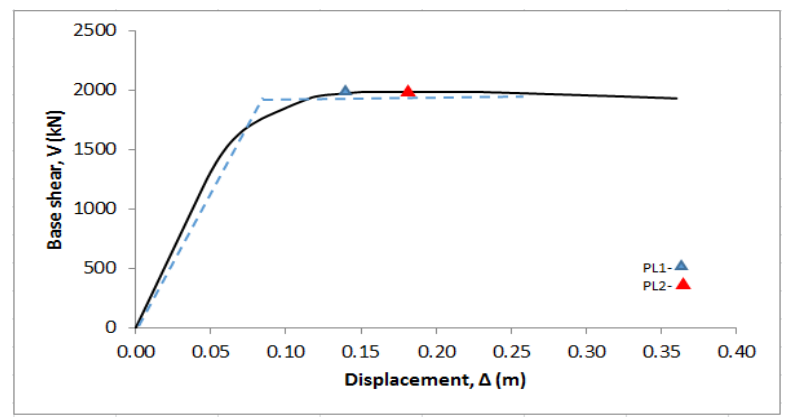

FigureIII. Pushover curve for fixed base

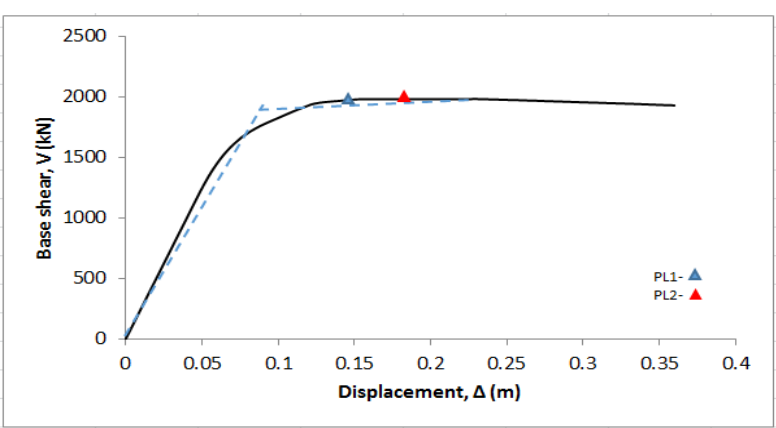

FigureIV. Pushover curve for hard soil

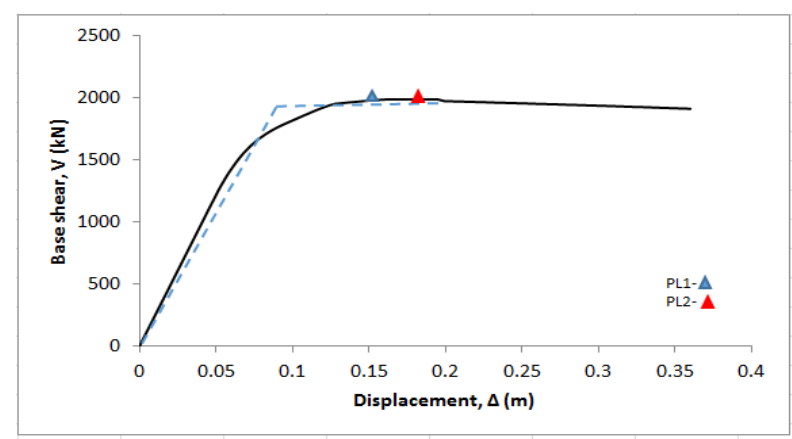

FigureV. Pushover curve for medium soil 


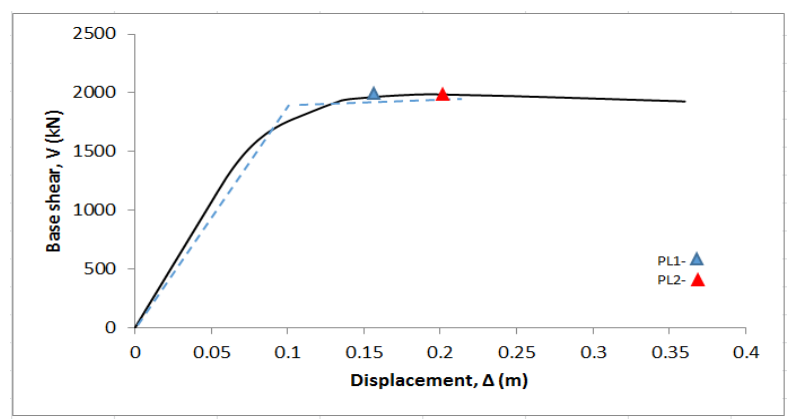

FigureVI. Pushover curve for soft soil

TABLE VIII shows the values of seismic base shear, ' $R$ ' factor and its key components over strength factor and ductility factor for considered water tanks for fixed base and flexible base with three different soil conditions. It is observed that soil flexibility of supporting soil has considerable effect on response reduction factor, base shear and ductility factor of water tank. It is also observed that as the soil flexibility increases from fixed base to soft soil base, the value of time period increases. The increase in the flexibility of the soil, reduces the over strength factor as well as ductility factor. The evaluated value of ' $R$ ' factor ranges from 4.1 to 2.65 and 5.37 to 3.3 for the performance limit PL1 and PL2 respectively for different soil conditions. If soil flexibility is not taken into account in estimating ' $R$ ' factor of elevated water tank properly; the accuracy in evaluating seismic base shear using static method, assessing the structural safety, facing earthquakes could not be reliable.

TABLE VIII. $\quad$ COMPONENT OF 'R' BASED ON PL1 \& PL2

\begin{tabular}{|c|c|c|c|c|c|c|c|c|}
\hline \multirow{2}{*}{$\begin{array}{l}\text { SOIL } \\
\text { TYPE }\end{array}$} & \multirow{2}{*}{$\begin{array}{l}\mathrm{V}_{0} \\
(\mathrm{kN})\end{array}$} & \multirow{2}{*}{$\begin{array}{l}\mathrm{V}_{\mathrm{d}} \\
(\mathrm{kN})\end{array}$} & \multirow[t]{2}{*}{$\mathrm{R}_{\mathrm{s}}$} & \multirow[t]{2}{*}{$\mathrm{R}_{\mathrm{r}}$} & \multicolumn{2}{|c|}{ PL1 } & \multicolumn{2}{|l|}{ PL2 } \\
\hline & & & & & $R_{\mu}$ & $R$ & $R_{\mu}$ & $R$ \\
\hline FIXED & 1985 & 965 & 2.05 & 1 & 2.01 & 4.12 & 2.62 & 5.37 \\
\hline HARD & 1983 & 931 & 2.12 & 1 & 1.94 & 4.11 & 2.50 & 5.30 \\
\hline MEDIUM & 1981 & 1215 & 1.63 & 1 & 1.97 & 3.21 & 2.50 & 4.07 \\
\hline SOFT & 1978 & 1431 & 1.38 & 1 & 1.92 & 2.65 & 2.40 & 3.30 \\
\hline
\end{tabular}

\section{CONCLUSION}

In this study the ' $\mathrm{R}$ ' factor of existing $\mathrm{RC}$ elevated water tank considering soil-flexibility are evaluated. This study may prove useful in formulating guidelines for evaluation of ' $R$ ' factor for seismic design of elevated RC frame water tank unified with soil flexibility. The important outcomes of current study are summarized as follows:

- It is observed that flexibility of supporting soil has considerable effect on displacement ductility and response reduction factor of water tank. 
- The impact of the SSI in case of soft and medium soil reduces values of ' $\mathrm{R}$ ' factor as much as $22 \%$ and $38 \%$ for the considered tanks respectively as compared to fixed base condition. The impact of the soil-flexibility is the least in case of hard soil.

- The impact of the SSI in case of soft and medium soil reduces values of displacement ductility ' $\mu$ ' factor as much as $3 \%$ and $11 \%$ as compared to fixed base for considered tank respectively.

- The actual value of ' $R$ ' expected to be lower than what is evaluated here, because of several reasons, such as, due to dimensions disproportion may lead to moderate torsional effects, due to deficiency in construction, not following the IS provisions for ductile detailing, etc.

\section{References}

[1] A Mondal, S Ghosh and G.R Reddy, "Performance -based evaluation of the response reduction factor for ductile RC frames" Engineering structures."2013,Vol-56

[2] K tamboli and J A Amin, "Evaluation of response reduction factor of RC braced frame " Journal of material and engineering structure. 2015

[3] M Masoudi, S Eshghi and M Ghafory-Ashtiany, 'Evaluation of response modification factor ' $R$ ' of elevated concrete tanks.2012,Vol-39

[4] R Livaoglu and A Dogangun, "An investigation about the soil-structure interaction effects on sloshing response of the elevated tanks" World conference on Earthquake engineering.2008

[5] R. Ghateh, M.R Kianoush and W. pogorzelski, "Seismic response factor of RC pedestal in elevated water tanks" Engineering structures.2015,Vol-87

[6] S Dutta, A Mamdal and S.C Dutta, "Soil-structure interaction in dynamic behaviour of elevated tanks with alternate frame staging configurations" Journal of sound and vibration.2004,Vol-277

[7] T Patel, J A Amin and B Patel, "Evaluation of response reduction factor of RC framed staging elevated water tank using static pushover analysis" International journal of civil and structural engineering.2014,Vol-4

[8] G Gazetas, "Analysis of machine foundation vibrations: state of art" International Journal of soil dynamics and earthquake engineering. 1983

[9] E Miranda,, and V.V Bertero, : "Evaluation of strength reduction factors for earthquake resistantdesign", Earthquake Spectra.1994, Vol-10, 357-379.

[10] ATC 19 "Structural Response Modification Factors" Applied Technology Council, Redwood city, California, 1995

[11] ATC ATC-40: "Seismic evaluation and retrofit of concrete building", vol. 1.Redwood City (USA): Applied Technology Council; 1996.

[12] BIS IS 1893: "Criteria for earthquake resistant design of structures" Part 1. New Delhi (India): Bureau of Indian Standards; 2002.

[13] BIS IS 456: "Plain and reinforced concrete-code of practice"New delhi (India): Bureau of Indian standards; 2000

[14] BIS IS 13920: "Ductile detailing of reinforced concrete structure subjected to seismic forced-code of practise"New delhi (India): Bureau of Indian standards; 1993.

[15] IITK-GSDM guidelines: "Seismic design of liquid storage tanks", NICEE;2007. 